\title{
Haematological Abnormalities in Visceral Leishmaniasis Patients Attending Gondar University Hospital; Retrospective Study
}

\author{
Eyasu Tesfaye ${ }^{1, *}$, Kinfe Fissehatsion ${ }^{1, *}$, Bethelihem Terefe ${ }^{2}$, Bamlaku Enawgaw ${ }^{2}$ \\ ${ }^{1}$ Department of Laboratory, Addis Ababa City Administration Health Bureau, Gandhi Memorial Hospital, Addis Ababa, Ethiopia \\ ${ }^{2}$ Department of Medical Laboratory Science, School of Biomedical and Laboratory Sciences, College of Medicine and Health Sciences, \\ University of Gondar, Gondar, Ethiopia
}

\section{Email address:}

eyasutesfaye1@gmail.com (E. Tesfaye),kfissehatsion@gmail.com (K. Fissehatsion), betch.nym@gmail.com (B. Terefe), bamlak21@gmail.com (B. Enawgaw)

${ }^{*}$ Corresponding Authors

\section{To cite this article:}

Eyasu Tesfaye, KinfeFissehatsion, Bethelihem Terefe, Bamlaku Enawgaw. Haematological Abnormalities in Visceral Leishmaniasis Patients Attending Gondar University Hospital; Retrospective Study. International Journal of HIV/AIDS Prevention, Education and Behavioural Science. Vol. 3, No. 5, 2017, pp. 48-53. doi: 10.11648/j.ijhpebs.20170305.11

Received: October 16, 2017; Accepted: November 3, 2017; Published: November 25, 2017

\begin{abstract}
Visceral Leishmaniasis (VL) or kalazar is a fatal neglected tropical disease caused by protozoan parasites of the genus Leishmania, belonging to the family Trypanosomatidae. Leishmania donovani complex are the causative agents of Visceral Leishmaniasis in Ethiopia and its burden is a public health problem where every year health facilities report thousands of cases and hundreds of deaths. Hematological abnormalities are the common presentation for human with Visceral Leishmaniasis, which comprises anemia, leucopenia and thrombocytopenia. Therefore; this study aimed to assess hematological abnormalities among Visceral Leishmaniasis patients attending Gondar University Hospital using a cross sectional study design. Socio-demographic data on 414 Visceral Leishmaniasis patients having complete records on hematological parameters collected from the laboratory log book and hospital chart by using a structured data collection sheet. Data was entered and analyze by using SPSS version 20. From the total 414 Visceral Leishmaniasis patients, 405(97.8\%) were males and $9(2.2 \%)$ were females. The overall magnitude of anemia, leucopenia, thrombocytopenia, neutropenia and Lymphopenia was $94.4 \%, 95.4 \%, 90.1 \%, 90.1 \%$ and $37.9 \%$ respectively. There was a significant association between age and prevalence of anemia, neutropenia and thrombocytopenia. The finding of the study shows with predominant existence of anemia, leucopenia and thrombocytopenia. Thus, specific diagnosis and monitoring of hematological abnormalities is required for early treatment of the disease and decreases mortality rate due to these abnormalities.
\end{abstract}

Keywords: Visceral Leishmaniasis, Anemia, Leucopenia, Thrombocytopenia

\section{Introduction}

\section{Back ground}

Leishmaniasis is groups of parasitic diseases caused by more than 20 species of obligate intracellular protozoa of the genus Leishmania. It occurs in three forms: visceral, cutaneous and mucocutaneous [1]. The disease is endemic in 62 countries with a total of 350 million people at risk and 12 million people are infected worldwide [2]. Visceral Leishmaniasis (kalazar) is the most severe form of Leishmaniasis that mainly causes systemic reticuloendothelial disease. Leishmania donovani complex are the causative agents of Visceral Leishmaniasis in Ethiopia and its mode of transmission is through bites of phelobotomine sand flies [2]. It is the second largest parasitic killer in the world second to malaria [3-5].

Visceral Leishmaniasis parasites are found in two forms: amastigote and promastigote. The amastigote form exists and proliferates in the mononuclear phagocytic system (MPS), especially spleen, liver and bone marrow. This leads to hyperplasia of the MPS with resultant disturbances in phagocyte bearing of organs and producing hematological manifestations. Hence, the spleen, in particular becomes 
massively enlarged. Other clinical manifestations include hepatomegaly, fever and a peculiar gray discoloration of the skin of the hands, feet, abdomen and face, which give the name "kala azar," or "black disease," to the condition [6]. Different laboratory diagnosis can be performed to diagnose Visceral Leishmaniasis. These includes serological test, microscopic examination of parasite in tissue, culture of bone marrow specimen which more sensitive than microscopic examination and hematological diagnosis like direct visualization of amastigote in tissue [7].

Hematological abnormalities are common complication of patients having Visceral Leishmaniasis since the disease is a chronic illness which is characterized by irregular fever, hepatosplenomegaly and panctyopenia, progressive weakness and emaction which can result to death if left untreated [8]. In addition, the spleen size and duration of illness correlate with some of the main hematological features [6]. On the other hand; hematological system in the form of bone marrow and peripheral blood changes are seen in Visceral Leishmaniasis patients such as anemia (normochromic normocytic anemia), leucopenia (especially neutropenia) and thrombocytopenia are common abnormalities [6, 8]. Granulocytic and megakaryocyte morphology has been reported to be unaltered except for an increase in immature forms in some cases [8]. From Visceral Leishmaniasis related hematological abnormalities, anemia is the most common abnormalities [9, 10]. Its cause is multifactorial; sequestration and destruction of red blood cells in large spleen, immune mechanism and alteration in blood RBC membrane permeability $[11,12]$.

\subsection{Statement of the Problem}

Visceral Leishmaniasis is a disease of major public health importance leading to severe mortality rate worldwide that accounts $90 \%$ if untreated and $5-30 \%$ for treated patients [1315]. This Visceral Leishmaniasis infection has been reported from 62 countries [14] with an estimated 500000 persons are affected every year globally [4]. In Africa at least 4,000 deaths are reported annually. The worst recorded epidemic probably killed 100,000 people in the western upper Nile area of Southern Sudan [16]. In Ethiopia Visceral Leishmaniasis has been reported from at least 40 areas, with the most endemic areas are Metema and Humera lowlands of Northwest, which accounts for $60 \%$ of the total burden [17]. The disease is characterized by fever, hepatosplenomegaly, anemia, leucopenia and Thrombocytopenia [8].

Anemia is almost always present in Visceral Leishmaniasis, which is frequently of normochromic normocytic type. Patients of Visceral Leishmaniasis generally have hemoglobin levels in the range of 7 to 10 $\mathrm{gm} / \mathrm{dl}$. The prevalence of anemia in Visceral Leishmaniasis patients occur mostly, because of several factor include hemolytic, chronic disease, opportunistic infection, and certain nutritional deficiencies. Hemolysis is the major cause of anemia this problem [11, 12] though there may also be plasma volume expansion associated with massively enlarged spleen. The reticuloendothelial hyperplasia limits the bone marrow response to hemolysis [18].

Thrombocytopenia is also one of the hematological changes in Visceral Leishmaniasis patients where Platelets counts can adversely affected after long duration of illness [19], because the duration of illness is significantly longer in thrombocytopenic patients compared to non thrombocytopenic. Reports confirm that VL disease decrease platelet production and lead to thrombocytopenia [20]. Moreover; Leucopenia is also one of the hematological abnormalities from patients complained with Visceral Leishmaniasis patients [8, 9].

Leucopenia appears even before any significant growth of reticuloendothelial cells in the marrow. There is reduction in the number of polymorphonuclear Neutrohpil to around $8 \%$ from normal of about $20 \%$ in bone marrow. This is the earliest change which takes place in the marrow which occurs at the same time when leucopenia starts to appear in peripheral blood. The lymphocytes and monocytes are normal in number, but the ratio of granulocytes to non granulocytes is reduced. However; the percentage of plasma cells is increased to about $2.8 \%$ from normal percentage of about $0.4 \%$. In the late stage of the disease, the eosinophilic myelocyes and mature Eosinohpil are greatly reduced. It has been observed that the decrease in leukocyte-erythrocyte ratio is directly proportional to the increasing size of spleen in Visceral Leishmaniasis [20, 21, 23, 24].

\subsection{Significant of the Study}

The prevalence of Visceral Leishmaniasis have account high worldwide particularly in endemic countries including Ethiopia. Similarly the fatal effect of the disease in relation to hematological features is one concern where attentions have not yet get and there is limited baseline data on Visceral Leishmaniasis related to hematological abnormalities in Ethiopia. Therefore; the goal of this study is to deliver information to clinicians about the prevalence of hematological abnormalities, which may contribute in improving the management of individuals infected with Visceral Leishmaniasis through early diagnosis and preventing complications resulted from such outcome. Besides; the finding of the study may serve as base line data for future researchers who have interested in similar topics.

\section{Method and Materials}

\subsection{Study Design, Period and Area}

An institution-based cross sectional retrospective study conducted from records of 2009-2013 data during April 2014 at the University of Gondar Hospital kalazar research and treatment center. The hospital is located in North Gondar around $747 \mathrm{~km}$ away from the capital city, Addis Ababa, which acts as the Leishmaniasis research and treatment center.

\subsection{Population}

All cases of Leishmaniasis patients in Gondar University 
Hospital (GUH) were used as a source of population where as Patients diagnosed for visceral Leishmaniasis (VL) and having complete records of hematological parameters were consider as a study population.

\subsection{Sample Size Calculations and Data Collection}

The sample size calculation was based on single sample size estimation principle [25]. Since similar prevalence rate were not done, the prevalence rate (p) taken as 50\%. From this, a sample size calculated as 414 (including $8 \%$ nonresponse rate). Data had collect from VL registrations book available at the kalazar research and treatment centre after confirming full information have basically recorded. The data extraction sheet consists of sex, age, hematological parameters and parasitic load. Hematological parameters such as hemoglobin, Hematocrit, white blood cell count, white blood cell differential count and platelet count were collected. Patient who are diagnosed for VL and having complete data for hematological parameters included in the study but patients who had missed either of the above information were exclude from the study.

\subsection{Quality Control}

The quality of data controlled at different levels for completeness and consistency. In order to increase the quality of data, the collected data had check by secondary personnel where data entry, analysis, extraction were assured complete but if errors found, correction would done.

\subsection{Data Analysis and Interpretation}

First the data cleaned and checked for completeness. Then data entered in to SPSS version 20 statistical software for analysis. The descriptive statistics used to give a clear picture of dependent and independent variables. Chi-square test computed as measure of association where P-value $<0.05$ considered as statistically significant. The data was present with tables, graphs, and charts.

\subsection{Ethical Consideration}

The study was conduct after obtaining approval letter from School of Biomedical and Laboratory Sciences and permission asked from hospital authorities. Since this study done on secondary data available at the kalazar research and treatment centre of Gondar University Teaching Hospital, no consent paper used. However, confidentiality is kept by using codes instead of names for all patient related data. Furthermore, all the coded patient information was kept confidentially.

\section{Result}

\subsection{Socio-demographic Characteristics}

From the total 414 patients having Visceral Leishmaniasis, $405(97.8 \%)$ was male with 45:1 male to female ratio. The mean average of respondents had $25.7 \pm 6.9$ years, where majority of them were 15-25 years of age 257(62.1\%) and 157(36.7\%) were within the age range of 21-25 years (Figure 1).

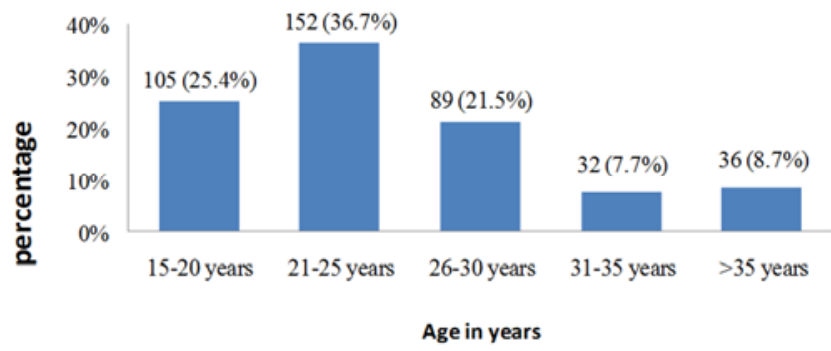

Figure 1. Age distribution of Visceral Leishmaniasis patients attending kalazar research and treatment center of Gondar University Hospital from 2009 - 2013.

\subsection{Laboratory Findings}

The range of $\mathrm{WBC}$ for all patients was $0.4-8.3 \times 10^{3}$ cells $/ \mu 1$, within the mean of $1.87 \pm 1.17 \times 10^{3} \mathrm{cells} / \mu \mathrm{l}$, hemoglobin was $1.2-18.5 \mathrm{~g} / \mathrm{dl}$, within the mean of $8.36 \pm 2.55 \mathrm{~g} / \mathrm{dl}$ and platelet was $2-370 \times 10^{3}$ cells $/ \mu 1$, within mean of $79.68 \pm 57.6 \times 10^{3}$ cells $/ \mu \mathrm{l}($ Table -1$)$.

Table 1. Hematological parameters of Visceral Leishmaniasis patients attending kalazar research and treatment center of Gondar University hospital from $2009-2013$.

\begin{tabular}{llll}
\hline Parameters & $\begin{array}{l}\text { Range }(M i n i m u m ~ \\
\text { Maximum) }\end{array}$ & Mean & SD \\
\hline $\mathrm{WBC}\left(\times 10^{3} / \mu \mathrm{l}\right)$ & $0.4-8.3$ & 1.87 & 1.17 \\
$\mathrm{Hgb}(\mathrm{g} / \mathrm{dl})$ & $1.2-18.5$ & 8.36 & 2.55 \\
$\mathrm{HCT}(\%)$ & $8.5-57.9$ & 25.08 & 7.00 \\
Granular cell $\left(\times 10^{3} / \mu \mathrm{l}\right)$ & $0.13-6.64$ & 0.85 & 0.69 \\
Lymphocyte $\left(\times 10^{3} / \mu \mathrm{l}\right)$ & $0.12-4.06$ & 0.8 & 0.5 \\
Monocytes $\left(\times 10^{3} / \mu \mathrm{l}\right)$ & $0.02-2.86$ & 0.21 & 0.25 \\
$\mathrm{PLT}\left(\times 10^{3} / \mu \mathrm{l}\right)$ & $2-370$ & 79.68 & 57.6 \\
\hline
\end{tabular}

\subsection{Hematological Abnormalities}

Anemia: WHO classification for reference range of hemoglobin state that hemoglobin level having less than $12 \mathrm{~g} / \mathrm{dl}$ for females and less than $13 \mathrm{~g} / \mathrm{dl}$ for males indicates anemia. The mean hemoglobin concentration was $8.36 \pm 2.55 \mathrm{~g} / \mathrm{dl}$ that indicates $94.4 \%(391 / 414)$ of patients were having anemia. In this study the prevalence of anemia in male and female was $94.3 \%(382 / 405)$ and $100 \%(9 / 9)$ respectively (Table 1).

Leucopenia, Neutropenia and Lymphopenia: According to WHO standard value, total white blood count $<4000$ cells $/ \mu$, Neutrohpil count $<1500$ cell $/ \mu 1$ and lymphocyte count $<600$ cell/ $\mu 1$ are indicator of Leucopenia, Neutropenia and Lymphopenia respectively. From the 414 VL patients, 95.4\% (397/414) of patients shown leucopenia, 90.1\% (373/414) showed neutropenia and $37.9 \% \quad(157 / 414)$ showed Lymphopenia (Table 1).

Thrombocytopenia: Platelet count below $150 \times 10^{3}$ cells $/ \mu 1$ indicates thrombocytopenia where $90.1 \%$ (373/414) of the respondents had developed thrombocytopenia (Table 1).

Anemia severity

The severity of anemia depends on the hemoglobin level where $\mathrm{Hgb}<8 \mathrm{~g} / \mathrm{dl}$ have termed as sever, $\mathrm{Hgb}=8-10 \mathrm{~g} / \mathrm{dl}$ (moderate) and $\mathrm{Hgb}=10-12 \mathrm{~g} / \mathrm{dl}$ (mild). Based on this 
classification, from anemic patients, majority of them 195 (47.1\%) shows severe anemia (figure 2).

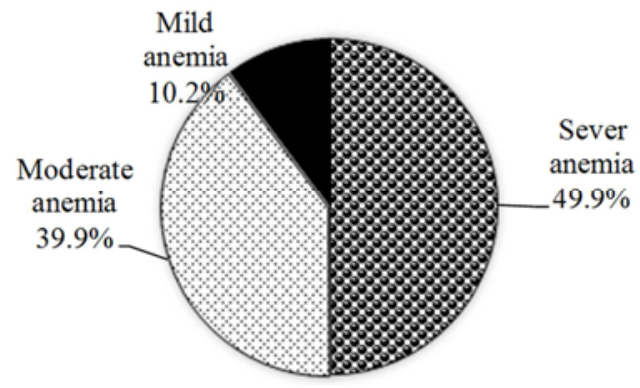

Figure 2. Severity of anemia among Visceral Leishmaniasis patients attending kalazar research and treatment center in Gondar University Hospital from 2009 - 2013.

\subsection{Parasitic Load}

Parasitic load was use to check the effectiveness of treatments. This was done by counting Leishmania donovani bodies with high power field from bone marrow aspiration and other aspiration which graded as $1+, 2+, 3+, 4+, 5+$ and
6+. Majority of visceral Leishmaniasis patients were $1+$ and $2+$ which accounts $24.9 \%$, and $20 \%$ of the cases respectively (Figure 3).

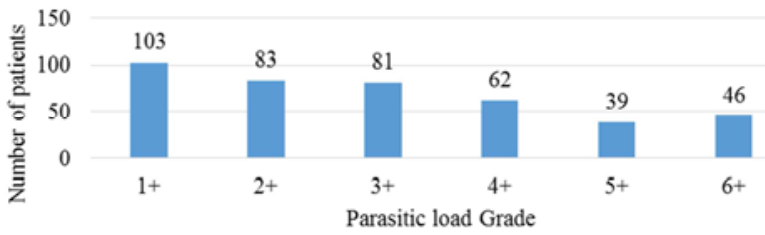

Figure 3. Parasitic load of Visceral Leishmaniasis patients at kalazar research center and treatment in University of Gondar Hospital from 2009 2013

\subsection{Association of Hematological Abnormalities with Sex and Age}

In this study there was no association between prevalence of anemia and sex $(P=0.372)$. Similarly leucopenia and thrombocytopenia did not have significant relationship with sex $(\mathrm{P}=0.284$ and 0.315$)$ respectively (Table 2$)$.

Table 2. Hematological disorder across sex in Visceral Leishmaniasis patients at kalazar research and treatment center of Gondar university hospital from 2009 - 2013.

\begin{tabular}{|c|c|c|c|c|}
\hline \multirow{2}{*}{ Hematological abnormalities } & \multicolumn{2}{|l|}{ Sex } & \multirow{2}{*}{$\mathbf{X}^{2}$} & \multirow{2}{*}{ P-value } \\
\hline & Male N (\%) & Female N (\%) & & \\
\hline Anemia & $382(94.3)$ & $9(100)$ & 0.797 & 0.372 \\
\hline Leucopenia & $389(96)$ & $8(88.9)$ & 1.146 & 0.284 \\
\hline Neutropenia & $364(89.9)$ & $9(100)$ & 1.011 & 0.315 \\
\hline Lymphopenia & $153(37.8)$ & $4(44.4)$ & 0.166 & 0.683 \\
\hline Thrombocytopenia & $364(89.9)$ & $9(100)$ & 1.011 & 0.315 \\
\hline
\end{tabular}

The prevalence of anemia and thrombocytopenia had significant relationship with age $(\mathrm{P}=0.000$ and 0.003 respectively) but did not have significant relationship with leucopenia and other variables (Table 3).

Table 3. Hematological disorder across age in Visceral Leishmaniasis patients at kalazar research and treatment center of Gondar University Hospital from 2009-2013.

\begin{tabular}{|c|c|c|c|c|c|c|c|}
\hline \multirow{2}{*}{ Hematological abnormalities } & \multicolumn{5}{|l|}{ Age } & \multirow{2}{*}{$\mathbf{X}^{2}$} & \multirow{2}{*}{ P-value } \\
\hline & 15-20yrs & 21-25yrs & 26-30yrs & 31-35yrs & $>35 y r s$ & & \\
\hline Anemia & $100(95.2)$ & $145(95.4)$ & $80(89.9)$ & $30(93.8)$ & $26(72.2)$ & 23.76 & 0.000 \\
\hline Leucopenia & $102((97.1)$ & $148(97.4)$ & $84(94.4)$ & $30(93.8)$ & $33(91.7)$ & 3.779 & 0.437 \\
\hline Lymphopenia & $34(32.4)$ & $62(40.8)$ & $34(38.2$ & $14(43.8)$ & $13(36.1)$ & 2.415 & 0.660 \\
\hline Thrombocytopenia & $98(93.3)$ & $144(94.7)$ & $77(86.5)$ & $24(75)$ & $30(83.3$ & 16.198 & 0.003 \\
\hline
\end{tabular}

Note: Numeric values in bold show statically significant association

\section{Discussion}

Anemia, leucopenia especially neutropenia and thrombocytopenia are most common hematological problem present in VL patients as reported in different findings [8,9]. In line, this study has shown higher magnitude of anemia, leucopenia and thrombocytopenia with a prevalence rate of $94.4 \%, 95.4 \%$ and $90.1 \%$ respectively. This prevalence of hematological abnormalities may be because of large number of parasite that affects reticuloendothelial system such as liver, spleen and bone marrow, since VL have direct effect in these organs to increase their sizes and decrease production of the blood.
The hemoglobin count was ranged from $1.2-18.5 \mathrm{~g} / \mathrm{dl}$ with mean $8.36 \pm 2.55 \mathrm{~g} / \mathrm{dl}$ and the prevalence of anemia was 94.4\%which is similar with study done at Armed Forces Institute of Pathology, Rawalpindi Pakistan (94.3\%) [21] and Nepal $(90 \%)$ [23]. Prevalence of anemia in this study was lower than study done in Saudi Hospital, Hajjah Republic of Yemen (100\%) [22] and in Dayanand Medical Collage and Hospital, Ludhiana (100\%) [6]. The difference may be due to difference in study population, socio-demographic characteristic, study design and cut-off levels of Hgb for anemia determination. In case of severity of anemia, severe, moderate and mild anemia was $49.9 \%, 39.9 \%$ and $10 \%$ respectively. This severity may be due to destruction of 
erythrocytes and decrease production of red blood cells, because it was directly affected by parasite. Similarly prevalence of leucopenia was $95.4 \%$ with average leukocyte count of $1.87 \pm 1.17 \times 103 / \mu \mathrm{l}$ (ranged from $0.4-8.3 \times 10^{3} / \mu \mathrm{l}$ ), which was higher than study done in Saudi Hospital Hajjah Republic of Yemen (81\%) [22], Nepal (67.5\%) [23], Dayanand Medical Collage and Hospital Ludhiana (83.3\%) [6], Armed Forces Institute of Pathology Rawalpindi Pakistan (40\%) [21]. This difference may be due to socio-demographic characteristics, and study population; in addition it may be due to delayed presentation to hospital which was attributing to hypersplenism since hypersplenism may cause leucopenia.

Especially neutropenia was commonly found in VL patients in this study. It was found on $90.1 \%$ of the study population, which was higher than study done in Nepal (27.5\%) [23]. This increases of neutropenia may be due to destroyed premature white blood cell (especially Neutrohpil) by parasite. Prevalence of thrombocytopenia had $90.1 \%$ with platelet count ranged from $2-370 \times 10^{3} / \mu \mathrm{l}$ with mean $\left(79.68 \pm 57.6 \times 10^{3} \mathrm{~g} / \mu \mathrm{l}\right)$ which were higher than study done in Armed Forces Institute of Pathology Rawalpindi Pakistan (15.7\%) [21], Nepal (56\%) [23], Saudi Hospital Hajjah Republic of Yemen (72.5\%) [22] and in Dayanand Medical Collage and Hospital Ludhiana (73.3\%) [6]. The difference may be due to socio-demographic characteristics, study population and study methods. Although this increases of thrombocytopenia in this study was due to sequestration of platelet.

In relation to sex majority of them $(94.3 \%)$ was males but all female patients were anemic in contrast to study done in Armed Forces Institute of pathology, Rawalpindi Pakistan which shows male have predominant with anemia [21]. Moreover; leucopenia was $96 \%$ in males and $88.9 \%$ in females where as prevalence of thrombocytopenia was $89.9 \%$ in males and $100 \%$ in females. In this study age showed significance association with anemia $(\mathrm{P}=0.000)$, Neutropenia $(\mathrm{P}=0.006)$ and thrombocytopenia $(\mathrm{P}=0.003)$. Age groups between 21-25 year patients were most affected groups with all hematological abnormalities.

\section{Limitation of the Study}

The study did not include pre-disposing factors that may aggravate the burden of the infection and increase hematological abnormalities. Furthermore; the crosssectional nature of the study has also its own limitation.

\section{Conclusion}

The principal changes in peripheral of patient with visceral Leishmaniasis are reduced number of red blood cells, reduction in leukocytes and decreased platelet count. This finding indicates high magnitude of hematological abnormalities of visceral Leishmaniasis (anemia, leucopenia (especially neutropenia) and thrombocytopenia). Mean while the hematological parameters of clients had adversely increased and patients may have a chance of developing chronic problems other than visceral Leishmaniasis infection that may have co-morbid effect. Furthermore; hematological abnormalities associated with age of patients were in need of age specific interventions in order to halt the co-morbid effect of the infection. The examination of parasite load in bone marrow aspiration used to follow patients with Visceral Leishmaniasis and majority of the study participants scored grade one and two parasitic load respectively. Therefore; Patient suspected for Visceral Leishmaniasis particularly endemic parts of Ethiopia is better to screen out for further hematological parameters and get early treatment in order to decrease mortality related to hematological abnormalities. Besides, further prospective study is recommended to find out associated risk factors of hematological abnormalities of Visceral Leishmaniasis parasite.

\section{References}

[1] World health organization. The world health report: improving, Performance. Geneva, 2000. Available at:http://www.who-int/htr.accessed on 16/12 /2013

[2] Atifa S, Wajiha R, Iffat Al, Zeeshan Z, Sumaira Z, Fatima K, Muhammad UA. Visceral Leishmaniasis- A study of 42 cases. Ann.Pak.Inst.Med.Sci.2009; 5(3):151-153.

[3] World health organization. The world health report. Geneva, 2001. Available at:http://www.who-int/htr.accessed on $23 / 12 / 2013$

[4] World health organization. The Leishmaniasis and Leishmania /HIV Co-infection, fact sheet, 2000; 116. Available at:http://www.ncbi.nlm.gov/pubMed.Accessed on 16/12/2013

[5] Desjeux P. The increase of risk factors for Leishmaniasis worldwide. Trans R Soc Trop Med Hyg. 2001; 95: 239-243.

[6] Varma N, Naseem S. Hematologic Changes in Visceral Leishmaniasis/ Kala Azar. Indian J Hematol Blood Transfus. 2010; 26(3):78-82.

[7] Bain BJ, Lewis SM, Practical hematology: Preparation and staining methods for blood and bone marrow films. $10^{\text {th }} \mathrm{ed}$. Churchill Livingston, Philadelphia. 2006; 59-78.

[8] Dhingra KK, Gupta P, Saroha V, Setia N, Khurana N, Singh T. Morphological findings in bone marrow biopsy and aspirate smears of visceral kalaazar. Indian J PatholMicrobiol. 2010; 53:96-100.

[9] Dube B, Arora A, Singh VP, kumar K, Sunder S. Platelet function studies in indiankala-azar.J Trop Med Hyg. 1995; 98(3):166-168

[10] Aikat BK, Mohanty D, Pathania AGS. Hematological investigations in kala azar in Bihar. Indian J Med Res.1979; 70:571-58.

[11] Woodroff AW, Topley E, Knight R, Downie CGB. The anaemia of kala-azar. Br J Hematol. 1972; 22:319-329.

[12] Pippard MJ, Moir D. Mechanism of anaemia in resistant visceral leishmaniasis. Ann Trop Med Parasitol.1986; 80:317

[13] Hamid GA, gobah GA. cilinical and hematological manifestation of visceral Leishmaniasis in Yemen children. TurkJ Hmatol. 2009;26:25-28 
[14] Elsheikh A, mahgoub M, Alkebsi A. visceral Leishmaniasis in children. The medical journal of cairo university. 1996; 64: 107-1011

[15] Orainey AL, Gasim IO, Singah YI. Visceral Leishmaniasis in Gizan, Auadi Arabia. Ann suadi Medicine. 1994;14:396-99

[16] Ali A, Ashford RW. Visceral Leishmaniasis in Ethiopia. IV. Prevalence, incidence and relation of infection to disease in an endemic area. Ann Trop Med Parasitol.1994; 88:289-293.

[17] Hailu A, Gebre-Micheal T, Berhe $\mathrm{N}$ and Balkew $\mathrm{M}$. Epidemiology and Ecology of Health and disease in Ethiopia: Leishmaniasis in Ethiopia. Shama press, Addis Ababa. 2006:615-634.

[18] Livotti S, Fischer A, Hematological and serological aspects of Mediterranean kala azar in infancy and childhood. Acta Trop. $1980 ; 37: 351$.

[19] Marwaha N, Sarode R, Gupta RK, Garewal G, Dash S Clinico-hematological characteristics in patients with kalaazar, a study from North-West India. Trop Geogr Med.1991;43:357-362.
[20] Al-Jurrayan AM, Al-Nasser MN, Al-Fawaz IM, Al-Ayed IH, Al-Herbish A, Al-Mazrou AM, Al-Sohailbani MO. The hematological manifestations of visceral Leishmaniasis in infancy and childhood. J Trop Paediatr.1995; 41:143-148.

[21] Naveed SS, Raza N, BuxH, Firdous M, Rafi B. Aclinicohaematological study of visceral Leishmaniasis from northern Pakistan. MC. 2011;17(3):54-57

[22] Haidar NA, Dai ABL, El-sheikh AM. Visceral Leishmaniasis in Children in Yemen. Saudi Med J. 2001; 22(6):516-519.

[23] Agrawal Y, Sinha AK, Upadhyaya P, Kafle SU, Rijal S,. Khanal B. Hematological profile in visceral Leishmaniasis. Int J Infect Microbiol. 2013; 2(2):39-44.

[24] Neki N. S and Jaswinder S. Hematological changes in Visceral Leishmaniasis. Int. J. Curr. Res. Med. Sci. 2017; 3(6): 36-40.

[25] Naing L, Winn T, Rusli1 BN. Practical Issues in Calculating the Sample Size for Prevalence Studies. Archives of Orofacial Sciences. 2006; 1: 9-14. 